Archived version from NCDOCKS Institutional Repository http://libres.uncg.edu/ir/asu/

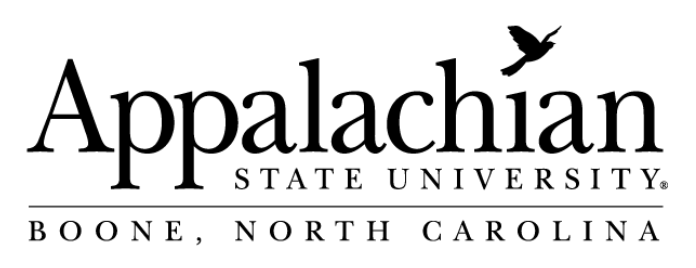

\title{
A Million Little Blogs: \\ Community, Narrative, and the James Frey Controversy
}

\author{
By: Mark Nunes
}

No Abstract

Nunes, Mark (2011) "A Million Little Blogs: Community, Narrative, and the James Frey Controversy" The Journal of Popular Culture, Vol. 44, No. 2, 2011 Version of Record Available from www.wiley.com 


\title{
A Million Little Blogs: Community, Narrative, and the James Frey Controversy
}

\author{
MARK NUNES
}

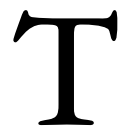

HE TITLE OF THIS ARTICLE, OF COURSE, IS A REFERENCE TO JAMES Frey's widely read and by now infamous memoir, A Million Little Pieces. But it is also a reference to the growing blogosphere, well beyond a million little weblogs-estimated, in fact, at around one hundred million in 2007, and growing at a rate of around five million new blogs a month. ${ }^{1}$ The story of the controversy is a tangled tale of communication in the contemporary moment, involving three high profile media figures-James Frey, Oprah Winfrey, and Larry King-along with an audience of millions of readers, television viewers, and bloggers. But it is also a tale of community and the ways in which a narrative structures itself in an informatic society.

In 2003, James Frey published a memoir that purported to describe his experience as a young tough with a growing chemical dependency. The book sketched out his descent into the underworld of addiction, his struggle to stay clean, and his emergence into a life free of drugs and alcohol. In the fall of 2005, Oprah Winfrey chose A Million Little Pieces for her book club. As with every other title blessed by Oprah, the book was an overnight sensation, quickly becoming a nationwide bestseller and quickly turning Frey into the new voice of addiction and recovery. The story gets a bit more complicated some three months after Frey's appearance on The Oprab Winfrey Show, when the Web site The Smoking Gun (TSG) published a piece entitled "A Million Little Lies: The Man Who Conned Oprah," claiming that the author had fabricated significant portions of the book, including several central plot details. 
The Smoking Gun is by no means a hard-hitting news site. A unit of Turner Entertainment Digital Network, the site provides its readers with access to "cool, confidential, quirky" documents through Freedom of Information Act requests ("About The Smoking Gun"). Along with news reports, court subpoenas, and sworn affidavits documenting the public scandals and legal entanglements of the rich and famous, the site boasts a rather impressive collection of celebrity mug shots. It was in this context that James Frey first came to TSG's attention. In searching for criminal records on Frey, they encountered discrepancies between his report of events and the actual criminal record. The "Million Little Lies" article describes a set of exchanges between TSG and Frey starting in December 2005, in which TSG attempted to get Frey to discuss the disputed details. Things came to a head on January 6, 2006, when William Bastone, editor for TSG, received a letter from Frey's lawyer, advising him that any attempt to publish a story disputing Frey's veracity "will expose you and all involved ... to substantial liability" (Singer 1). On the following day, Frey posted what The Smoking Gun article refers to as a "preemptive strike," by posting TSG's letter on his own blog. According to TSG:

Frey explained that he was posting our letter to inform his fans of the "latest attempt to discredit me ... So let the haters hate, let the doubters doubt, I stand by my book, and my life, and I won't dignify this bullshit with any sort of further response."

(“A Million Little Lies”2)

The next day, on January 8, The Smoking Gun posted its article-and the media storm ensued.

While Frey's book had sold in the millions by early January, blog discussion of the book and the author was rather light in the run-up to The Smoking Gun article. With the exception of a blip of activity after the first Oprah Winfrey Show appearance in October, the blogs show a low, but steady interest, with an expected swell in references to the title during the winter holiday/best books of the year publishing period. According to the Web site Technorati ${ }^{2}$ (http://www.technorati.com), which tracks blog activity, blog interest in Frey spikes on January 10 and 11, corresponding with his appearance on Larry King Live, and peaks two days later when it was announced that future copies of the book would contain a publisher's note concerning its "embellishments." Blog activity remains high and then spikes again on January 
27 and 28, corresponding with Frey's second appearance on The Oprah Winfrey Show. Blog activity finally drops off after February 3, when Frey's "apology" was released, and Random House announced its plans to include the apology in all future printings of the book. ${ }^{3}$

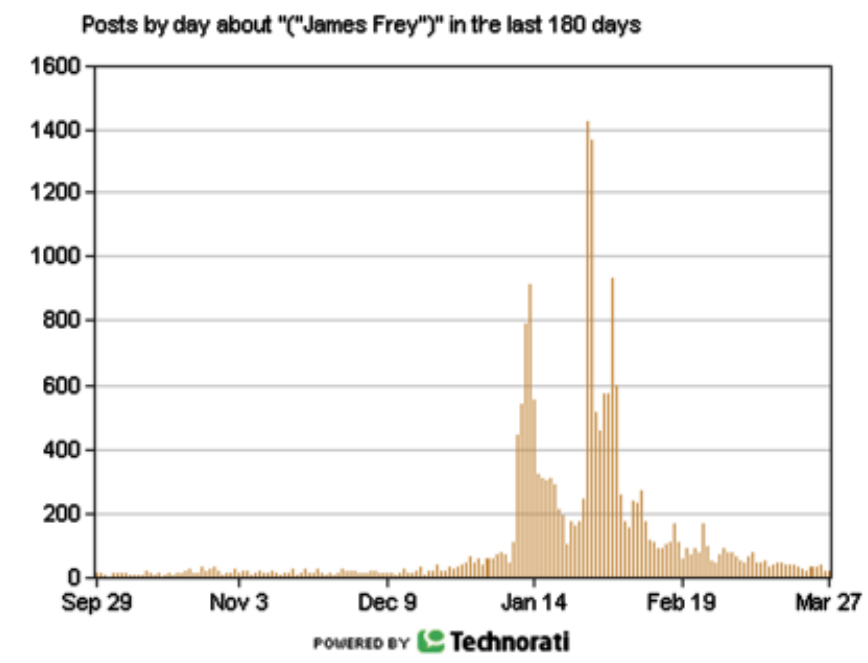

As might be expected, after the million little pieces hit the fan, the message board on Frey's own Web site, BigJimIndustries.com, was swamped with postings. According to the March, 2006 Wikipedia account of the events (as good a source as any on the life of a blog), the site closed and was redesigned without the message board, but by the end of January the board was back in place. Frey impersonators began posting to Oprah's and Frey's own discussion boards, prompting the following response from Frey on January 30, his first posting to his site since his Larry King appearance: "I am not posting anything on any message boards, including the board at this site. Anything posted in my name was not written by me, and is not a statement by me in any way whatsoever" ("James Frey"). We will return to this concern over the authenticity of online posting (however ironic it might appear in this context); it is worth noting at this point, however, the speed at which the Web site attracted hundreds of postings. In the months that followed, the discussion board on the BigJimIndustries.com Web site developed into a support-community of sorts (some fifty plus pages of threaded posts in the first three months of 2006 alone): postings 
that support Frey as an author and as a fellow addict, postings of addicts and alcoholics supporting each other, and postings that record the banality of daily community interactions (movie and music recommendations, birthday greetings, etc.) Over the next few months the site would change its format somewhat-adding a chat feature, organizing discussion board postings by topic, designating "member" and "nonmember" features-but this "community of support" element remained (and still remains) a foregrounded feature. As of July 2007, eighteen months after TSG's exposé, readers of A Million Little Pieces were still posting to James Frey's site to share their appreciation of the bonesty of his memoir, and to share words of frustration and support to other readers recovering from and struggling with addiction.

This community aspect of the Frey affair raises a number of interesting questions, in part because the book, the controversy, and the ongoing blog activity represent at least three distinct, yet overlapping communities. First is the community of readers. ${ }^{4}$ While one might argue that any text serves as a context for community by providing a shared frame of reference for social contact, Frey's chosen genrememoir-and its status as an Oprah Book Club pick amplify this inherent communal function to the extent that the genres of memoir and talk show alike share the rhetorical form of ritualized public revelation of personal life. The Oprab Winfrey Show is predicated upon the notion that coming forward and bearing one's message—sharing one's "story"-creates a connection with the audience that in turn creates community. Although Frey personally disavows twelve-step programs, his book takes part within a similar rhetoric of recovery: that "carrying one's message" creates a larger community of recovery in its attempt to "reach out" to the suffering addict and alcoholic. Oprah's book club makes this function explicit at two levels: first, through the talk show format, in which the intimate exposure of the guest presumably brings benefit to the audience; and second, through the prescriptive of a book club reading list, creating an imagined community in a sense quite parallel to Benedict Anderson's original use of the term, where the conspicuous consumption of a text serves to establish membership in a community of like-minded individuals.

But one need not actually read A Million Little Pieces to be a member of Oprah's Book Club, which in effect defines the second community evoked by the Frey controversy. The "community of viewers" aspects of 
a mass media broadcast are amplified in the instance of The Oprab Winfrey Show to the extent that, in both form and content, Oprah addresses her studio audience and her mass-mediated audience as a collective "we"-what Margaret Morse describes as a mode of "engagement" that blurs community-oriented intersubjectivity and media-oriented interactivity (14-23). As Laurie Haag notes, the confessional aspects of The Oprah Winfrey Show places Oprah within a tradition of female talk show hosts who evoke the structures of intimate conversation in their attempt to have their guests speak from and to the heart $(116-17)$. The audience does not watch so much as witness. In the same conventions of twelve-step recovery that Frey eschews, Oprah's guests promise to share their "experience, strength, and hope" with a community of viewers in a format that is simultaneously public and intimate. "Carrying a message" implies a set of relations that exceeds simple transmission of information. It takes place in the ritualized social spaces of private confession and public revelation. The Oprah Winfrey Show produces what John Silk has called "mediated quasi-interaction," in which the televised appearance of "a fellow sufferer" creates a form of identification that, while initiated through mass media "may lead to involvement in geographically and socially extensive self-help and mutual support networks" (179). To some degree, Oprah Winfrey and Larry King, the other mass media figure of importance here, mark poles on this spectrum. Whereas Oprah's show works to establish intimacy and structures itself as a domestic, feminine space of what Haag calls "girl talk," King's show, from the suspenders to the microphone prop, structures talk around the concept of "news." While hardly an intimate setting, Larry King Live marks a mediated space of revelation not unlike Oprah's couch. As such, the audience watching the show participates in a ritualized event. They are not simply receivers of the news; they are participants in a "mediated quasi-interaction" - a communal revelation.

It is important to note, however, that the media storm surrounding A Million Little Pieces occurred not in response to the rise of a mediated community of the heart, but rather in response to The Smoking Gun's allegations of misrepresentation. As Elizabeth Bird notes, "scandal stories, like other stories, bring changing mores into sharp focus through media narratives and the popular discussion that takes off from those narratives, whether in homes, workplaces, or on the Oprab Winfrey Show" (44). In the instance of the Frey controversy, the intersection of 
media narrative and popular discussion marks a third mediated community, to the extent that the Internet provided a many-to-many forum for the propagation of an unfolding scandal. While book sales soared after Oprah's endorsement and Frey's subsequent appearance on her talk show, the blog activity was, as noted above, relatively low. Unlike the community of the heart evoked by the confessional mode of The Oprab Winfrey Show, or the imagined community of readers evoked by the book itself, the community of bloggers only began to participate in large numbers in circulating the Frey story once it became a story of representational veracity. Certainly a number of these blogs were taking part in by now a fairly well established relation between blogs and the mass media, in which blogs function as "media filters." Yet it would seem that the particular nature of Frey's transgression acted as a catalyst for blog activity: he did not merely misrepresent the facts; he misrepresented bimself. If media scandals are, as Bird suggests, "moral dramas in extravagant terms" that say much about the culture and community in which they spread, we have much to learn in considering how and why the community of bloggers took hold of this story (48).

\section{$* * * * *$}

As a scandal of misrepresentation, Frey's tale parallels the saga of Plain Layne, Kaycee Nicole Swenson, and other infamous blog "hoaxes," in which a large community of avid readers found that the life they had been following so closely online was not at all what it appeared to be. As John Jordan notes, when Kaycee Nicole's readers discovered that the teenage girl who had fought leukemia for two and a half years before dying of a brain aneurism was really the creation of Debbie Swenson (Kaycee's "mother"), the blog community, while united in its vilification of Debbie's transgression, were rhetorically divided between those who felt all online identities were suspect and those who maintained that trust in honest renderings of the heart provided the social foundation for online community. As one blogger commented, "Shame on 'Debbie' and who ever else was involved, but as for the rest of you, I still love you all!" (qtd. in Jordan 207). The scarequotes are of interest here, in this diacritical attempt to distinguish between persona and the personal, between signs of the digital avatar and an electronic language of the heart. But as Jordan notes, drawing on Mark Poster's concept of underdetermination, ${ }^{5}$ while online community depends upon a dialogic interplay between the presentation of 
identity and an audience's acceptance (and hence construction) of that identity, "when it came to Debbie's subjectivity, community members rhetorically negated the dialogic view of identity as a strategy for preserving their community and their own innocence" (Jordan 207).

Of equal interest, however, is that the resultant confession did not dispel this online community, but actually provided — for a period at least-opportunity for heightened activity. As reported in the New York Times, some fifty bloggers and community participants (dubbing themselves the Scooby Doos) began examining data and trading information back and forth in an attempt to get to the truth of Kaycee Nicole-a hunt that continued on even after Debbie Swenson's confession (Hafner G1). ${ }^{6}$ As Hafner notes, "The incident is revealing not only for what it says about the Internet as safe redoubt for deception but also for the role it played when dozens of people, at once curious and angry, became electronic gumshoes and used the Web to root out the fraud" (G1). A similar phenomenon occurred when Plain Layne's well-read blog ended abruptly in 2004 after some three years with the discovery by "Internet sleuths" that Layne was not a twentysomething young woman coming of age in the IT world, but was actually a thirty-something young man named Odin Soli, engaged in a fiction project (Boese). Not only did the blog attract, according to Soli's figures, some 500,000 readers; it also generated a community of Plain Layne trackers, who shared information and reciprocal links in an attempt to establish the "real identity" of the writer. In this context, we might begin to understand the spike in "James Frey" references along similar lines, as blogs attempted to answer the question: is James Frey really who he claims to be? The story of James Frey's misrepresentation of himself becomes, in other words, the real story-a story that develops and sustains itself in its circulation through the "blogosphere."

As Bird notes, the critical language of media scholars is often ill-suited for an analysis of scandal in that:

Journalism critics tend to define news in terms of how effective the text of news stories are at conveying information about the world to readers and viewers. They assume that readers consume news in order to learn facts about the world around them and be informed. In that respect, they follow what Carey (1989) calls a 'transmission' view of communication. (22) 
The reference to the work of James Carey, and his distinction between transmission and ritual views of communication, is quite appropriate to a discussion of the communities of discourse that developed onand offline in response to the Million Little Pieces controversy. In the transmission view of communication, geography and language coincide in the image of dispatch and delivery from point $\mathrm{A}$ to point $\mathrm{B}$. This view provides a central, dominant concept for our understanding of communication as "a process whereby messages are transmitted and distributed in space for the control of distance and people" (Carey 15). The second mode of communication, what Carey calls a "minor thread in our national thought," associates communication with various forms of communing (18). It is, as he notes, an archaic usage, listed as such in most dictionaries. His discussion of the term is worth quoting at length:

This definition exploits the ancient identity and common roots of the terms "commonness," "communion," "community," and "communication." A ritual view of communication is directed not toward the extension of messages in space but toward the maintenance of society in time; not the act of imparting information but the representation of shared beliefs. If the archetypal case of communication under a transmission view is the extension of messages across geography for the purposes of control, the archetypal case under a ritual view is the sacred ceremony that draws persons together in fellowship and commonality. (18)

Continuing in his reading of communication in the context of religion, he argues that ritual "sees the original or highest manifestation of communication not in the transmission of intelligent information but in the construction and maintenance of an ordered, meaningful cultural world that can serve as a control and container for human action" (18-19). Using the newspaper as an extended example, he notes that a ritual view of communication reveals the degree to which the act of reading reaffirms the reader's place within a social, economic, and moral sphere. Drawing in part on Durkheim, he suggests that in both secular and religious forms:

[The] projection of community ideals and their embodiment in material form-dance, plays, architecture, news stories, strings of speech-creates an artificial though nonetheless real symbolic order that operates to provide not information but confirmation, not to 
alter attitudes or change minds but to represent an underlying order of things, not to perform functions but to manifest an ongoing and fragile social process. (19)

The ritual model emphasizes the role of communication in establishing social cohesion - and coherence-in the form of imagined communities.

In the dominant transmission view of communication, the receiver functions as an operator to the extent that she is ultimately transcendent to the act of transmission itself. She is literally out of context. Carey's discussion of a transmission view of communication parallels Claude Shannon's general model for a communication system, which ultimately understands communication in terms of a channel that carries the signal from source to receiver. And as Carey's definition suggests, Shannon's model has "control issues" - namely providing a mathematical model for signal detection and noise reduction. It is, in other words, a cybernetic model of communication. Carey does not mention Shannon by name in his 1975 article, "A Cultural Approach to Communication," but clearly he is addressing what by then had become a dominant cybernetic model for communication. Once communication reduces to a flow of information, we no longer need to worry about context-just control. And that was exactly what the first revolution in cybernetics accomplished: a rupture in the link between context-laden meaning and context-free information. Selection precedes interpretation. Noise, then, in Shannon's model, is merely an unwanted source providing "spurious" information (Weaver 19). ${ }^{7}$ Shannon's communication system, defined as a cybernetic system, attempts to optimize output, honing actual performance from the range of possible outcomes of an operation (Wiener 24-25). ${ }^{8}$ While there is no arrow in Shannon's schematic feeding back from receiver to source, it is implied in the desirability of a one-to-one correspondence between signal at source and signal at receiver. The channel, in other words, is really a circuit. In this regard, cybernetics takes part in, and is a primary example of, Lyotard's "logic of maximum performance"-a legitimation that depends solely upon efficiency, predictability, and optimization (Postmodern xxiv). Cybernetics plays by the rules of this game, defining communication as a transmission within a field of givens that are in principle entirely knowable, calculable, and therefore predictable. 
While communication-as-transmission ultimately seeks to obey what Lyotard calls a performativity principle of maximum efficiency and maximum control, communication-as-ritual depends upon performance: a situationally specific calling forward of symbolic relations (Postmodern xxiv). In his critique of cybernetics' performativity principle in The Postmodern Condition, Lyotard calls attention to a crisis of legitimation in the "pragmatics of scientific knowledge," which can only affirm statements that can be assigned truth-values, directed toward provable referents. It has no system, however, to legitimate itself as a system of knowledge, other than through a process of delegitimating all other knowledge systems. The "pragmatics of narrative knowledge," on the other hand, allows for and incorporates a wide range of language games and ultimately legitimates itself in its actual performance $(18-23)$. As a ritual mode of communication, the story circle of narrative encloses the moment of telling and the context of telling in an act of social legitimation. A narrative culture, writes Lyotard, "finds the raw material for its social bond not only in the meaning of the narratives it recounts, but also in the act of reciting them" (22). The pragmatics of narrative knowledge defines the reciprocal relationship among communicative positions of teller, audience, and subject of the tale. Understanding communication as ritual allows us also to understand the means by which a narrative structures the social context for teller and tale alike. As Lyotard notes, "The knowledge transmitted by these narrations is in no way limited to the functions of enunciation; it determines in a single stroke what one must say in order to be heard, what one must listen to in order to speak, and what role one must play ... to be the object of a narrative" (21). The ritual view of communication foregrounds social and cultural context-and to some degree creates that context, much as a performative speech act both requires and reaffirms the specific speech situation that gives it its force. In contrast to the cybernetic circuit, ritual communication operates within the metaphorical structure of the story circle. "Story telling" is never about just getting the story across. It defines a distinctive social space, one that privileges a sharing of context over informatic exchange. As such, the ritual communication of narrative-storytelling-creates and is created by a communal experience, imagined or otherwise, defining matters of social inclusion and exclusion, cultural belonging and cultural challenge. 
To return to Frey's book, Oprah, and the million little blogs: the question becomes not a matter of what James Frey did or did not reveal or convey, but rather: how does the media event that propelled these communities establish and maintain a set of cultural values and concerns? Certainly Bird's analysis of media scandals is relevant here, in that the controversy surrounding A Million Little Pieces ultimately became a kind of "tabloid" story that played out the moral anxieties of the day. The story is a cautionary tale of sorts, about what to believe and about the nature of truth, deception, and revelation. As ritual communication in the narrative mode, the James Frey saga "communicates" a great deal in that it satisfies a sense of how the world works, for better or for worse. This is not to let Frey off the hook for his so-called literary embellishments. Rather, it is an attempt to acknowledge that in both its furious uptake as a memoir from the heart and the media storm that followed on The Smoking Gun's exposé, we might best understand the Frey controversy as a communicative event, one governed by the social structures of ritual and the pragmatics of narrative knowledge. As such, we might think of this event as marking a conflict in narratives within popular culture- a conflict that did not originate in or limit itself to the world of blogs, but which is best understood within this communicative context.

In this regard, then, blog response to the Frey controversy and various blog hoaxes such as Kaycee Nicole or Plain Layne is significant to the extent that it calls attention to the pragmatic context for a culturally defining event. If, as Bird argues, media scandals provide culturally relevant stories for a society, regardless of how "trivial" the news, then the Million Little Pieces controversy was scandalous not because Frey's transgression was so exceptional, but rather, because the challenges of mediated representation had long since become a recognizable feature of everyday life. The same month that Frey appeared on Oprah's couch, Stephen Beachy's feature, "Who is the Real JT LeRoy" appeared in New York magazine, describing the author's attempts to reveal the real person behind the persona who claimed to be a former "teenage hustler who'd been pimped out as a cross-dressed prostitute by his mother at truck stops throughout the South" (Beachy). When the James Frey story broke into discussion on the MetaFilter blog site in January, it erupted within a discussion of the ongoing literary unmasking of JT LeRoy — with the revelation that the ingénue who made media and A-list club appearances in the name of JT was in fact a 
woman by the name of Savannah Knoop ("JT Leroy [sic] De-Masked"). ${ }^{9}$ Far from being an uncommon event, such revelations have become habitually recurring instances of a cultural phenomenon best described by one MetaFilter blogger as "a Kaycee Nicole moment." ${ }^{10}$ In effect, A Million Little Pieces created a pragmatic context for a community of bloggers, many of whom had not even read the book: one that called attention to self-presentation as a central cultural concern, connecting James Frey, JT LeRoy, Kaycee Nicole, and a countless host of others whose selfhood is no longer self-evident. In the words of one MetaFilter contributor, who linked the Smoking Gun piece to the JT LeRoy post less than an hour after the story broke: "Looks like the sockpuppets are taking over the world" ("JT Leroy [sic] De-Masked").

The "sockpuppet" reference is quite revealing. While the JT LeRoy hoax and James Frey's biographical inaccuracies are "real world" instances of misrepresentation by way of traditional mass media, the comparison with Kaycee Nicole and the use of an Internet slang term ${ }^{11}$ for someone who creates an alternate identity online in order to deceive an audience would seem to indicate a shared set of assumptions concerning the thorny issue of identity-namely that today, on- and offline, the subject-position is not what it used to be.

A communication model based on "sockpuppetry" depends upon a transmission view of communication, in that it assumes that agents communicate through a medium and control the degree of accuracy that passes through an inherently ambiguous channel. Yet at some point, the sockpuppet becomes a social agent in its own right within the network of exchanges that define an online community. These increasingly common moments of drifting social agency mark an increasingly recognizable feature of everyday life in an informatic society. While for the blogging community Kaycee Nicole serves as a useful shorthand to call attention to the problem of trust in a domain in which identity is potentially unstable, one could track this conundrum of online identity to that mid-1980s ur-tale of Joan/Julie, ${ }^{12}$ the paraplegic online persona of a male psychiatrist who developed a strong, supportive connection with a number of women in CompuServe chat rooms, only to find himself incapable of controlling the social networks "Julie" had set in motion, or the strong feelings of betrayal he induced in others once he revealed his "true self." In all of these stories, from Joan/Julie to James Frey, what makes the news a "scandal" is not the betrayal of trust per se, but the fact that this betrayal lays bare a scene of contested values 
concerning agency and identity in an increasingly mediated society. To approach the scandal of sockpuppetry by way of a ritual view of communication (rather than the transmission view that it apparently assumes) would call attention to these online exchanges as a "dramatic action in which the reader joins a world of contending forces as an observer at a play" (Carey 21). There are contending forces at work here to the extent that, as Jordan notes in the blog response to Debbie Swenson's confession, the medium of identity-play is at the same time cast as a digital forum for a language of the heart (207-08). While a transmission view of communication forces us to question what gets transmitted, a communication-as-ritual view reveals the degree to which the performance of these social narratives-misrepresentation, circulation, revelation, denunciation - speaks to a core cultural conflict in American popular culture surrounding the nature of identity in a media-saturated society.

\section{$* * * * *$}

During the past decade and a half, two narratives dominated our understanding of online identity. The first suggested that online interaction allowed for a more direct mode of communication between participants, because users could cast off social artifice and speak from the heart (think Meg Ryan and Tom Hanks in You've Got Mail). The second narrative warned to trust no one online, because anyone could be posing as anyone else online, and probably was (as in Peter Steiner's New Yorker cartoon, "On the Internet, nobody knows you're a dog"). The James Frey story foregrounds the conflict between these two narratives, and the degree to which this conflict marks a broader social and cultural concern about the stability of the subject-position in a society increasingly dominated by circulations and flows. It is a conflict between a dominant ideology of the modern subject, as carried out on a majority of weblogs, and an ideology of identity predicated upon a fluid understanding of the postmodern self.

As Julie Rak notes, a majority of weblogs follow along a modernist, liberal interpretation of self as autonomous agent, privileging selfexpression. As such, the rhetoric of blogging depends upon self-disclosure, an ethics of honest self-revelation, and a generalized sense of the integrity of self. With the exception of the most cynical of responses to hoaxes such as that of Kaycee Nicole, participants in blog discussions of these scandals assume a shared "community ethos" based on the implicit or explicit belief in the possibility of "authentic online 
personae" (Jordan 208). Likewise, in his study of UK weblogging, Reed notes a dominant tendency in journal bloggers to claim "my blog is me," and asserts that violations such as Kaycee Nicole function as "an exception that proves the rule" $(227,241 n 4)$. What is more, Reed argues that for journal bloggers, the blog site does not merely represent the self; rather, it serves as a substitute self, which replicates online (albeit incompletely) a "me" that parallels offline subjectivity (227). This dominant ideology runs contrary to a tendency to treat online representation as an opportunity to experiment with alternate forms of identity construction. The fact that online presence demands a form of self-construction that substitutes "representation" for "the real" calls attention to the process by which identity is always a performance of representations. ${ }^{13}$ As Sandy Stone argues, we are all, in effect, multiple selves; the identity crises of "crossdressing psychiatrists" and Kaycee Nicoles are merely extreme examples of the fragmented, contingent "nature" of constructed identities. Thus, as Vincent Hevern points out, reading chronological entries of any one blog reveals a high prevalence of self-contradictory statements and points of view, often without comment or notice. "Threads" of identity, he argues, map negotiations of identity as a fluid, morphing self $(331-32)$.

The "contending forces" marked out by these two narratives of identity are not self-contradictory; rather, the dominant form and genre of blogging interpellates the Web blogger as a unified subject, while at the same time marking multiple, competing narratives that cannot answer to the hailings of the genre. In other words, we find two competing narratives of identity in the blogosphere: a dominant ideology of authenticity and a minor expression of a constructivist self. In Jordan's reading of the Kaycee Nicole affair, he suggests that the vehemence with which the blog community demonized Debbie was in part an attempt to assert this dominant ideology, while at the same time suppress the dialogic, constructivist nature of all self-representation on the Web. One might argue that the James Frey affair provided the blogging community with a "Kaycee Nicole Moment" precisely because Frey's violation of the memoir convention brought to the fore this same tension within a society dependent upon mediated self-representation: a tension between media as channels of the heart and media as arenas of narrative construction.

Clearly The Smoking Gun, as a form of "media filter" Web site, takes agency and authenticity seriously, as do a large number of bloggers. Yet 
the fact that the TSG revelations generated discussion in the mass media and in the blogosphere alike suggests that "the story" here is not one that can be quickly dismissed as a simple matter of lies and untruth. Note that, as Reed suggests, the dominant ideology of blogging denies the mediated quality of these texts, treating them as "channel[s]" for "brain dumps" (228). Such an account of blogging operates within a communication-as-transmission model, with the ultimate good conceived of as a "pure" channel. ${ }^{14}$ Frey, by fabricating details, violated the dominant ideology of communication-as-transmission by intentionally introducing error, thereby corrupting not only his own narrative, but the channel of communication itself, namely the cultural nexus marked by blogs, memoirs, and Oprah's couch.

In his introduction to the collection of essays, The Ethics of Life Writing, Paul John Eakin writes, "When life writers fail to tell the truth ... they do more than violate a literary convention governing nonfiction as a genre; this disobey a moral imperative" $(2-3)$. That moral imperative, he goes on to argue, has its roots in the historical connection in the modern West between autobiographical writing as a genre and "the emergence of the individual as a primary cultural value" (6). The primacy of the first-hand depends upon a primacy of the individual as both social agent and observer. Thus as Paul Lauritzen takes up in his discussion of the controversy surrounding factual inaccuracies in 1992 Nobel Prize winner Rigoberta Menchús account of human rights abuses in Guatemala:

If we are to invite others to engage in social action in part on the basis of appeals to experience, if experiential narratives are to inform practical deliberation, then we need to raise serious questions about the reliability and credibility of experiential narratives and their narrators. Did the events really happen? Is the narrator reliable? Are there competing narratives to which we must listen? These are the kinds of questions that we must answer if we are to draw on experiential narratives when deliberating morally. $(36-37)$

Frey's narrative of recovery and redemption clearly falls into this category of an experiential narrative that attempts a form of moral deliberation. And as with I, Rigoberta Menchú, one can attempt to dispel such questions of credibility by claiming either that A Million Little Pieces is exempt from such concerns because of its genre as memoir, or that while inaccurate in the details, the book sets forth a larger truth 
about the nature of addiction and recovery (Lauritzen 26-30). Frey's own negotiations as an author-the distinction he sets up between the genre of autobiography and the genre of memoir-suggest the same sort of conflict: that one can lie and tell the truth at the same time. One can also hear this conflict in Oprah Winfrey's attempt to suss out the truth of the book that somehow transcends the falsehoods that it contains. Likewise, for the community of Frey readers and for the community of support on his Web site, the "real story" still speaks, even as the concept of "the real" is itself a matter of flux. I would argue that these competing narratives - a narrative of the heart and a narrative of identity in flux-mark a central conflict in contemporary American popular culture.

While genre issues (memoir vs. autobiography, literary truth vs. literal truth) provide a foundation for much of the blog discussion in those first days following The Smoking Gun piece, these discussions took place within a medium and a genre in which (as Jordan notes with the Kaycee Nicole debate) users post using screen names, and the threat of the "sockpuppet" always plays in the background of any discussion. These blog exchanges are not merely conveying information related to the Frey controversy; they are establishing a cultural terrain for the performance of social concerns related to the nature of truth, revelation, and self-disclosure in a mediated, network society. An analysis of the Frey controversy, in the context of both the furious uptake of the topic on blog sites, and a background of several high-profile blog hoaxes, ${ }^{15}$ forces us to ask how blogs create a story circle rather than an informatic circuit —one that allows for a reversibility of teller, tale, and audience, which in turn legitimates a sense of community.

The Frey controversy and the voices and opinions of the million little weblogs suggest a "world of contending forces" in which identity and self-representation are very much up for grabs. We are increasingly comfortable with the idea that identity functions as a kind of memethat we are who we link to. MySpace and FaceBook play out in the same world as Plain Layne literary experiments and identity theft phishing schemes. At the same time, the desire for a forum-online with the bloggers, or on the couch with Oprah-that speaks from and to the heart still functions as a dominant ritual of communication that affirms who we are and where we belong in society. James Frey's A Million Little Pieces triggered the controversy it did because it speaks to both of these social narratives, and it played out the conflict of these contending 


\section{forces on the two screens that increasingly dominate our everyday life- screens that increasingly serve as the context for our ongoing commu- nicative rituals that define our place in the social world.}

\section{Notes}

1. The number of blogs and the rate of growth of the "blogosphere" are based on estimates generated by Technorati in 2007. The blog indexing site no longer provides this tally, but an archival "About Us" detailing these estimates is available at: "About Us," http:// web.archive.org/web/20071011163949rn_1/technorati.com/about/

2. Blog activity is based upon key word mention of the phrase "James Frey" on blogs tracked by Technorati. The data presented here in chart form was generated on March 27, 2006 by Technorati's dynamic charting function covering a period of 180 days: "Technorati Chart: James Frey," Technorati. The site no longer provides this functionality.

3. Blog activity would spike one last time in 2006 in September, in response to the announcement of a lawsuit settlement allowing readers to file for a refund. According to a New York Times account, readers must have purchased the book before January 27, 2006 and must "submit a sworn statement that they would not have bought the book if they knew that certain facts had been embroidered or changed" (see Motoko Rich, "James Frey and His Publisher Settle Suit Over Lies").

4. It would be more accurate, perhaps, to describe two overlapping communities of readers to distinguish between the readers of Frey's book back in 2003 and the Oprah Book Club readers in the fall of 2005 .

5. See Mark Poster, "A Culture of Underdetermination."

6. In one of the more impressive moments of cyber-detective work, one member discovered the true identity of the young woman in the basketball uniform whose image Debbie Swenson used to represent Kaycee Nicole, enlarging the photo to reveal the team name (the Lady Lions), the high school, and jersey number (see Katie Hafner, "A Beautiful Life, an Early Death, a Fraud Exposed").

7. As Warren Weaver explains in his comments of Shannon's work: "Information is a measure of one's freedom of choice in selecting a message. The greater the freedom of choice, and hence the greater the information, the greater is the uncertainty that the message actually selected is some particular one" (18-19) (see Warren Weaver, "Recent Contributions to the Mathematical Theory of Communication,").

8. This concept is perhaps most clear in a section of Norbert Wiener's The Human Use of Human Beings, where Wiener describes the legal system in terms of a cybernetic solution to "the problem of control and communication." He writes: "The technique of the interpretation of past judgments must be such that a lawyer should know, not only what a court has said, but even with high probability what the court is going to say" (110). Wiener describes cybernetics as a control system for increasing determination, and hence increasing order in the face of entropy, "nature's tendency to degrade the organized and to destroy the meaningful" (17). He writes: "the scientist is always working to discover the order and organization of the universe, and is thus playing a game against the arch enemy, disorganization" (34).

9. A separate thread started on the MetaFilter site some six hours after the news broke under the heading "A Million Little Pieces of BS."

10. The MetaFilter blog, it should be noted, has a well-established history of discourse built around the Kaycee Nicole hoax; in fact, the site was one of four forums examined by John Jordan in his study of the hoax: "A Virtual Death and a Real Dilemma: Identity, Trust, and 
Community in Cyberspace." As one contributor to the January 8, 2006 "JT Leroy [sic] De-Masked" discussion notes, the comparison between Kaycee Nicole and JT LeRoy had occurred some three months earlier on the site (see "JT Nicole?").

11. Numerous sites online define "sockpuppet" as a proxy identity that speaks in the name of a third party with the intent of creating an audience effect (e.g., posting a response to one's own blog using an alias account and user name) (see e.g., the Wikipedia entry for "Sockpuppet (Internet)").

12. See, for example, Allucquère Rosanne Stone, "In Novel Conditions: The Cross-Dressing Psychiatrist."

13. See, for example, Sherry Turkle's Life on the Screen for a Lacanian reading of online identity and the potentials for therapeutic intervention through virtual role-playing.

14. For another reading on James Carey and "conduits" of communication, see Ken Hillis, Digital Sensations. See also Hillis 137 - 50 for an alternate reading of "pure" communication channels as Neoplatonic conduits of "light."

15. Both the Kaycee Nicole and Plain Layne hoaxes crossed beyond the blogosphere and into the world of traditional print mass media (see, e.g., Chris Taylor, "10 Things We Learned About Blogs" and Hafner G1.

\section{Works Cited}

“About The Smoking Gun.” The Smoking Gun. Accessed on 20 Feb. 2011. $\langle$ http://www.thesmokinggun.com/about.html $\rangle$.

“About Us.” Technorati. Accessed on 20 Feb. 2011. 〈http://web.archive. org/web/20071011163949rn_1/technorati.com/about/ $\rangle$.

Anderson, Benedict. Imagined Communities. New York: Verso, 1991.

Beachy, Stephen. "Who is the Real JT LeRoy?" New York 17 Oct. 2005:30+. Accessed on 20 Feb. 2011. 〈http://nymag.com/nymetro/ news/people/features/14718/index.html $\rangle$.

Bird, S. Elizabeth. The Audience in Everyday Life. New York: Routledge, 2003.

Boese, Alan. "Plain Layne (and Other Fake Bloggers)." The Museum of Hoaxes. 22 Jun. 2004. Accessed on 20 Feb. 2011. 〈http:// www.museumofhoaxes.com/hoax/weblog/permalink/plain_layne $\rangle$.

Carey, James. "A Cultural Approach to Communication.” Communication as Culture. New York: Routledge, 1989. 13-36.

Eakin, Paul John. "Introduction: Mapping the Ethics of Life Writing." The Ethics of Life Writing. Ed. Paul John Eakin. Ithaca, NY: Cornell UP, 2004. 1-16.

Frey, James. A Million Little Pieces. New York: Nan A Talese, 2003.

Haag, Laurie. "Oprah Winfrey: The Construction of Intimacy in the Talk Show Setting." Journal of Popular Culture 26.4 (1993): $115-21$.

Hafner, Katie. “A Beautiful Life, an Early Death, a Fraud Exposed.” New York Times 31 May 2001: G1. 
Hevern, Vincent. "Threaded Identity in Cyberspace: Weblogs \& Positioning in the Dialogic Self." Identity 4 (2004): 321-35.

Hillis, Ken. Digital Sensations. Minneapolis: U of Minnesota P, 1999. 60-89.

“James Frey." Wikipedia. 27 Mar. 2006. Accessed on 20 Feb. 2011. 〈http://en.wikipedia.org/w/index.php?title=James_Frey\&oldid=4 5756754〉.

Jordan, John. "A Virtual Death and a Real Dilemma: Identity, Trust, and Community in Cyberspace." Southern Communication Journal 70.3 (2005): $200-18$.

"JT Leroy [sic] De-Masked." MetaFilter 8 Jan. 2006. Accessed on 20 Feb. 2011. 〈http://www.metafilter.com/48117/JT-LeroyDeMasked $\rangle$.

"JT Nicole?" MetaFilter 10 Oct. 2005. Accessed on 20 Feb. 2011. $\langle$ http://www.metafilter.com/45766/JT-Nicole $\rangle$.

Lauritzen, Paul. "Arguing with Life Stories: The Case of Rigoberta Menchú." The Ethics of Life Writing. Ed. Paul John Eakin. Ithaca, NY: Cornell UP, 2004. 19-39.

Lyotard, Jean-François. The Postmodern Condition: A Report on Knowledge. Minneapolis: U of Minnesota P, 1984.

"A Million Little Lies: The Man Who Conned Oprah." The Smoking Gun 8 Jan. 2006. Accessed on 20 Feb. 2011. 〈http://www.thesmokinggun. com/documents/celebrity/million-little-lies $\rangle$.

“A Million Little Pieces of BS.” MetaFilter 8 Jan. 2006. Accessed on 20 Feb. 2011. 〈http://www.metafilter.com/48121/A-million-littlepeices-of-BS $\rangle$.

Morse, Margaret. Virtualities: Television, Media Art, and Cyberculture. Bloomington: Indiana UP, 1998.

Poster, Mark. "A Culture of Underdetermination." What's the Matter with the Internet? Minneapolis: U of Minnesota P, 2001. 1-20.

Rak, Julie. "The Digital Queer: Weblogs and Internet Identity." Biography 28 (2005): 166-82.

Random "Publishers' Statement Regarding James Frey's Book." 26 Jan. 2006. Accessed on $20 \mathrm{Feb}$ 2011. 〈http://www.randomhouse.biz/ media/pdfs/AMLP012706.pdf $\rangle$.

Reed, Adam. "My Blog is Me': Texts and Persons in UK Online Journal Culture (and Anthropology)." Ethnos 70 (2005): 220-42.

Rich, Motoko. "James Frey and His Publisher Settle Suit Over Lies." New York Times 7 Sept. 2006: E1.

Shannon, Claude. "The Mathematical Theory of Communication." The Mathematical Theory of Communication. Eds. Claude Shannon and Warren Weaver. Urbana: U of Illinois P, 1949. 29-125. 
Silk, John. "Caring at a Distance." Ethics, Place, and Environment 1 (1998): $165-82$.

Singer, Martin. "Letter to William Bastone." The Smoking Gun 6 Jan. 2006. Accessed on $20 \mathrm{Feb}$. 2011. 〈http://www.thesmokinggun.com/ file/james-frey-legal-threat-letter $\rangle$.

"Sockpuppet (Internet)." Wikipedia. 2011. Accessed on 20 Feb. 2011. $\langle$ http://en.wikipedia.org/wiki/Sockpuppet_(internet) $\rangle$.

Soli, Odin. "Plain Layne 2001-2004." 2011. Accessed on 20 Feb. 2011. 〈http://web.archive.org/web/20070217205627/http://odin soli.com/plainlayne.htm $\rangle$.

Steiner, Peter. "On the Internet, Nobody Knows You're a Dog." Cartoon. New Yorker 5 Jul. 1993: 61.

Stone, Allucquère Rosanne. "In Novel Conditions: The Cross-Dressing Psychiatrist." The War of Desire and Technology at the Close of the Mechanical Age. Cambridge, MA: MIT, 1995. 65-81.

Taylor, Chris. "10 Things We Learned About Blogs." Time 27 Dec. 2004: $110-11$.

"Technorati Chart: James Frey." Technorati 27 Mar. 2006. Accessed on 27 Mar. 2006. 〈http://charts.technorati.com/chart/\%22James+Frey\% 22 ? chartdays $=180$ \&language $=$ en\&authority $=\mathrm{a} 4\rangle$.

Turkle, Sherry. Life on the Screen. New York: Simon \& Schuster, 1995.

Weaver, Warren. "Recent Contributions to the Mathematical Theory of Communication." The Mathematical Theory of Communication. Eds. Claude Shannon and Warren Weaver. Urbana: U of Illinois P, 1949. $1-28$.

Wiener, Norbert. The Human Use of Human Beings. Garden City, NY: Anchor, 1954.

You've Got Mail. Dir. Nora Ephron. Warner Bros., 1998. Film. 